\title{
Abordagens metodológicas na pesquisa biográfica
}

\author{
CHRISTINE DELORY-MOMBERGER \\ Universidade de Paris 13 \\ Tradução de Anne-Marie Milon Oliveira \\ Revisão técnica de Fernando Scheibe
}

Não se pode tentar definir com precisão as orientações e as práticas metodológicas da pesquisa biográfica sem articulá-las ao que constitui o objeto próprio a essa corrente de pesquisa. Em outras palavras, antes de abordar as questões de método, é necessário, pelo menos de forma breve, relembrar o que constitui o projeto epistemológico específico da pesquisa biográfica e o que o diferencia, por exemplo (mas não é um exemplo de todo inocente), da abordagem sociológica. Poderemos então tratar das questões de metodologia em dois níveis: 1) o da "coleta de materiais", no caso e de forma bem peculiar, da "entrevista de pesquisa biográfica"; 2) o da "análise dos materiais", em outros termos, dos modelos de leitura e de interpretação dos documentos coletados. Como veremos, a dificuldade aponta, ao mesmo tempo, para um objetivo a ser perseguido na abordagem dessas questões e para a adequação, a congruência entre as práticas metodológicas e o projeto específico da pesquisa biográfica. É, portanto, esse último que se faz agora necessário relembrar.

\section{O PROJETO EPISTEMOLÓGICO DA PESQUISA BIOGRÁFICA}

O projeto fundador da pesquisa biográfica inscreve-se no quadro de uma das questões centrais da antropologia social, que é a da constituição individual: como os indivíduos se tornam indivíduos? Logo, essa questão convoca muitas outras concernentes ao complexo de relações entre o indivíduo e suas inscrições e entornos (históricos, sociais, culturais, linguísticos, econômicos, políticos); entre o indivíduo e as representações que ele faz de si próprio e das suas relações com os outros; entre o indivíduo e a dimensão temporal de sua experiência e de sua existência. Examinemos alguns dos aspectos implicados num projeto dessa natureza. 


\section{O INDIVÍDUO COMO SER SOCIAL SINGULAR}

O objeto da pesquisa biográfica é explorar os processos de gênese e de devir dos indivíduos no seio do espaço social, de mostrar como eles dão forma a suas experiências, como fazem significar as situações e os acontecimentos de sua existência. E, conjuntamente, como os indivíduos - pelas linguagens culturais e sociais que atualizam nas operações de biografização - contribuem para dar existência, para reproduzir e produzir a realidade social ("linguagens" tem aqui um sentido muito amplo: códigos, repertórios, figuras de discurso; esquemas, scripts de ação etc.). Nessa interface do individual e do social - que só existem um por meio do outro, que estão num processo incessante de produção recíproca - o espaço da pesquisa biográfica consistiria então em perceber a relação singular que o indivíduo mantém, pela sua atividade biográfica, com o mundo histórico e social e em estudar as formas construídas que ele dá à sua experiência. Para dizê-lo de modo mais sintético: o objeto visado pela pesquisa biográfica, mediante esses processos de gênese socioindividual, seria o estudo dos modos de constituição do individuo enquanto ser social e singular (Delory-Momberger, 2003, 2005). Essa é, então, a singularidade que a pesquisa biográfica se dá por tarefa apreender, mas não é uma singularidade solipsista, é uma singularidade atravessada, informada pelo social, no sentido em que o social the dá seu quadro e seus materiais.

\section{A TEMPORALIDADE DA EXPERIÊNCIA}

A questão, então, é de saber em que a pesquisa biográfica poderia ser diferente de abordagens disciplinares, que, tudo bem analisado, visam aparentemente às mesmas questões, respondem aos mesmos objetos. Em que a pesquisa biográfica seria, por exemplo, distinta de uma sociologia do individuo, hoje em dia bem representada e preocupada, ela também, em dar conta da subjetividade e da experiência individual?

Parece-me que poderíamos responder: nisto que ela introduz a dimensão do tempo e, mais precisamente, da temporalidade biográfica da experiência e da existência. As ciências sociais têm dificuldade de dar conta da dimensão temporal da experiência individual: ainda, quando recorrem ao material biográfico, sua forma mais habitual de encaminhamento é colocar o tempo entre parênteses para reencontrar o "terreno" de uma geografia ou de uma cartografia do social. A postura específica da pesquisa biográfica é a de mostrar como a inscrição forçosamente singular da experiência individual em um tempo biográfico se situa na origem de uma percepção e de uma elaboração peculiar dos espaços da vida social.

\section{A BIOGRAFIZAÇÃO DA EXPERIÊNCIA}

Mas, uma vez reconhecida essa dimensão da temporalidade da experiência que abordagens como as da psicologia social e de certas correntes da sociologia contemporânea também levam em consideração -, ainda assim é preciso especificá-la sob o seu aspecto propriamente biográfico, no sentido forte em que o entendemos, o de "escrita da vida", de elaboração da experiência.

Alimentada por uma ampla tradição hermenêutica (Dilthey, Gadamer, Ricoeur) e fenomenológica (Berger, Luckmann, Schapp, Schütz), a pesquisa biográfica estabelece uma reflexão sobre o agir e o pensar humanos mediante figuras orientadas 
e articuladas no tempo que organizam e constroem a experiência segundo a lógica de uma razão narrativa. De acordo com essa lógica, o indivíduo humano vive cada instante de sua vida como o momento de uma história: história de um instante, história de uma hora, de um dia, de uma vida. Algo começa, se desenrola, chega a seu termo numa sucessão, superposição, empilhamento indefinido de episódios e peripécias, de provações e experiências. No cotidiano da existência, um grande número dessas operações de configuração tem uma dimensão de automaticidade e não solicita ativamente a consciência por corresponder aos scripts repetitivos dos quadros sociais e culturais. Ainda assim, essas operações estão sempre presentes, assegurando a integração da experiência que advém na temporalidade e na historialidade próprias à existência singular.

Assim, a atividade biográfica não fica mais restrita apenas ao discurso, às formas orais ou escritas de um verbo realizado. Ela se reporta, em primeiro lugar, a uma atitude mental e comportamental, a uma forma de compreensão e de estruturação da experiência e da ação, exercendo-se de forma constante na relação do homem com sua vivência e com o mundo que o rodeia. A utilização dos termos biografia e biográfico para designar não a realidade fatual do vivido, e sim o campo de representações e de construções segundo as quais os seres humanos percebem sua existência, enfatiza até que ponto essa compreensão narrativa da experiência se apresenta como uma escrita, isto é, como um modo de apreensão e de interpretação da vivência, com sua dinâmica e sua sintaxe, seus motivos e suas figuras. Os neologismos biografar(-se) e biografização salientam o caráter processual da atividade biográfica e remetem a todas as operações mentais, comportamentais e verbais pelas quais o indivíduo não cessa de inscrever sua experiência e sua ação em esquemas temporais orientados e finalizados.

\section{ABORDAGEM METODOLÓGICA I: O MATERIAL BIOGRÁFICO}

Se tal é o objeto conceitual que a pesquisa biográfica pode fixar para si, resta ainda definir o "terreno", o "material" mais apropriado para apreender esse objeto, para permitir sua observação e análise. Esse terreno e esse material são de natureza bem particular, já que o pesquisador não pode ter acesso a eles a não ser pelas entradas que os sujeitos lhe dão mediante os atos de biografização a que se entregam. Esses atos podem, evidentemente, assumir uma pluralidade de manifestações - mentais, comportamentais, gestuais -, mas a mediação privilegiada para se chegar às modalidades singulares segundo as quais o sujeito atualiza os processos de biografização é, incontestavelmente, a atividade linguageira, a fala que o sujeito mantém sobre si próprio. $\mathrm{O}$ falar de si recobre, por sua vez, formas diversas que têm relação com a pluralidade dos objetivos enunciativos e dos tipos discursivos que elas põem em funcionamento. Nelas encontraremos diferentes tipos de discurso: descritivo, explicativo, argumentativo, avaliativo etc. A pesquisa biográfica reconhece, todavia, um lugar particular à enunciação e ao discurso narrativo, na medida em que o narrativo, pelas suas características específicas, é a forma de discurso que mantém a relação mais direta com a dimensão temporal da existência e da experiência humana. Esclareçamos, aliás, que o relato, cujo fundamento e princípio de organização é constituído pelo discurso narrativo, 
acolhe muitas outras formas de discurso que descrevem, explicam, argumentam, avaliam as "ações" relatadas. ${ }^{1}$ É da maior importância reconhecer essa pluralidade discursiva do relato, pois é no entrecruzamento das formas de discurso que ele apresenta que se tornam potencialmente acessíveis os sistemas de tematização e de valorização utilizados pelo narrador.

\section{A “ENTREVISTA DE PESQUISA BIOGRÁFICA"}

Mas fiquemos, por enquanto, nas modalidades de coleta dessa fala do sujeito e tentemos, em particular, tornar claro o que se refere à entrevista biográfica, ou melhor, tornar visível o que diferencia esta de outras formas de entrevista, ao que poderíamos chamar de "entrevista de pesquisa biográfica".

\section{A finalidade da entrevista de pesquisa biográfica: apreender a singularidade de} uma fala e de uma experiência

Qualquer que seja o quadro ou o campo do estudo mobilizado (mulheres imigrantes, alunos em situação de fracasso, jovens em busca de inserção etc.), a finalidade da entrevista é mesmo colher e ouvir, em sua singularidade, a fala de uma pessoa num momento $\mathrm{x}$ de sua existência e de sua experiência. $\mathrm{O}$ fato de esta fala (e a experiência que relata) ser atravessada pela história, pelo social, pelo político, de ser em grande parte feita de representações, crenças coletivas, de discursos alheios, em suma, o fato de ela ser uma fala de sua época e de sua sociedade é plenamente reconhecido pela pesquisa biográfica que vai mais além: faz dela uma dimensão constitutiva da individualidade. Em decorrência disso, o investigador em pesquisa biográfica deve ter o conhecimento mais preciso possível do campo e dos contextos em que desenvolve sua observação: não com o objetivo de distinguir, na fala dos seus entrevistados, o que seria da ordem do coletivo e o que seria da ordem do individual, para distinguir e separar o que seria exterioridade social e interioridade pessoal, e sim para darem-se os meios de apreender e compreender as biografias individuais, isto é, os espaços-tempos singulares que cada um configura a partir da conjugação de sua experiência (e da historicidade de sua experiência) e dos mundos-de-vida, dos mundos de pensar e agir comuns de que participa. O devir biográfico é sempre o produto de uma interação entre a ação dos indivíduos e o determinismo das estruturas. E a maneira como as pessoas dão conta (também a si próprias), pelo relato, dos caminhos e processos por meio dos quais se constituíram não pode deixar de recortar as estruturas sincrônicas e diacrônicas que modelam os percursos individuais. Todavia, o que a entrevista de pesquisa biográfica procura apreender e compreender é justamente a configuração singular de fatos, de situações, de relacionamentos, de significações, de interpretações que cada um dá à sua própria existência e que funda o sentimento que tem de si próprio como ser singular.

1 Conviria aqui precisar que as sequências de ação configuradas no relato têm, nelas próprias, uma dimensão e uma função argumentativa. 


\section{Entrevistar-se com: um duplo espaço heurístico}

Quem entrevista quem na entrevista de pesquisa biográfica? Em outras palavras: de que (de quem?) é constituído o espaço de pesquisa, o espaço heurístico da entrevista? Pelo menos de três componentes: duas pessoas, o entrevistador e o entrevistado, que ocupam posições diferentes (voltaremos a isso); e o que se passa, o que "se mantém" entre essas duas pessoas: atitudes, colocações, formas de intercâmbio e de ação recíprocas. Muito se falou, e com razão, da implicação ao mesmo tempo institucional e pessoal do pesquisador e da maneira como ela vem inflectir, modificar a interlocução, agindo sobre a fala do entrevistado. Talvez se tenha falado menos da implicação do entrevistado, que pode ajustar suas palavras em razão das expectativas do entrevistador. Além disso, e sobretudo na entrevista de pesquisa biográfica, ele é levado a conduzir seu próprio "projeto de pesquisa", já que o que lhe é explícita ou implicitamente solicitado é a realização de um trabalho de investigação, de definição de sua própria forma, e a compreensão deste trabalho constitui o objeto específico do pesquisador. A entrevista de pesquisa biográfica instaura assim um duplo empreendimento de pesquisa, um duplo espaço heurístico que age sobre cada um dos envolvidos: o espaço do entrevistado na posição de entrevistador de si mesmo; o espaço do entrevistador, cujo objeto próprio é criar as condições e compreender o trabalho do entrevistado sobre si mesmo.

\section{A condução da entrevista: seguir os atores}

A especificidade dessa situação de dupla pesquisa leva à problematização das formas que a "condução da entrevista” assume. Para além das conhecidas distinções entre entrevistas "diretivas", "semidiretivas", "não diretivas"- que tendem a formalizar e a diferenciar dispositivos de entrevista segundo as formas de questionamento e as formas de respostas que induzem (fechadas, restritas, abertas) -, é o lugar, o estatuto da própria questão e do questionador que devem ser aqui interrogados.

A concepção que se costuma ter da forma da entrevista e da sua dinâmica repousa na ideia falsamente simples de que o entrevistador (o pesquisador) pergunta e o entrevistado (o informante) responde. Num tal quadro, o perguntador hábilé aquele que, tendo, ao mesmo tempo, um conhecimento suficiente do campo e certo senso psicológico, faz as perguntas certas que vão trazer, senão as respostas certas, pelo menos as respostas boas para ele, o entrevistador. E fica, sem dúvida, evidente que esse modelo funciona quando a entrevista, como é frequentemente o caso, obedece a uma função de ilustração e de demonstração de uma (hipó)tese colocada de forma preliminar e que busca, para se sustentar a si mesma, os argumentos concretos que os relatos de vida lhe fornecem. Nesse caso, as perguntas e as respostas podem ser declaradas certas à medida que permitem responder a este dispositivo argumentativo: toda a habilidade do perguntador consiste então, de fato, em fazer aquele que responde (e é isso que ele é, propriamente, um in-formante) ir na direção da tese que ele quer produzir. Também, nesse caso, somente será retido pelo entrevistador (e, sem dúvida, só será audível para ele) aquilo que contribuir para ilustrar ou defender sua tese. Todo o resto será rejeitado (ou sequer será ouvido) como algo lateral, não pertinente.

Tudo muda quando o narratário (que não é mais um perguntador) tem o projeto de deixar expandir-se da maneira mais ampla e mais aberta possível o espaço 
da fala e das formas de existência do narrador, quando ele se coloca na posição de "seguir os atores". A ordem canônica e quase ontológica da pergunta antecedente e da resposta consecutiva só pode ser, então, invertida. Em se tratando de seguir os atores, o narratário não pode mais anteceder o narrador, só pode correr atrás dele e tentar ficar o mais perto possível dele nas sinuosidades, nas bifurcações, nas rupturas dos seus caminhos e dos seus desvios, sem nunca ultrapassá-lo. Ao se manter até o fim esta posição (de epistemologia e de método), chega-se a esta afirmação paradoxal: a questão do narratário só pode vir depois, seu questionamento só pode ser ulterior.

Será que essa maneira de "ver as coisas" é sustentável? Será que a inversão de ordem entre pergunta e resposta permite manter ainda um sentido para sua relação, ou será que significa sua abolição pura e simples enquanto pergunta e resposta? Parece que enquanto se permanece no quadro puramente retórico da pergunta/ resposta e de sua distribuição regrada entre pesquisador e pesquisado, ou mesmo entre narratário e narrador, não se pode escapar a uma forma de aporia. Mas talvez o paradoxo seja somente aparente e possa, por sua vez, ser produtivo: sob a condição de que se distribua de outra maneira, entre os dois polos da entrevista, o espaço da pergunta e o da resposta; de que se reencontre o que está em jogo na entrevista biográfica e que se resitua, do lado certo, o lugar do perguntador e o do perguntado.

Quem é o verdadeiro perguntador numa entrevista biográfica? Aquele que fala e conta de si ou aquele que ouve e recebe? Aquele que está passando pela prova do seu relato e, por meio dele, das suas formas de existência ou aquele que recolhe as provas deste questionamento? E quem é o verdadeiro interrogado? Aquele que, mediante seu relato, põe a funcionar a hermenêutica prática de sua existência ou aquele que busca ouvir e entender esse trabalho de interpretação? Não será este último o primeiro a ser interrogado quanto à sua maneira de tornar presente e inteira a fala que lhe é destinada e de fazer significar, não para ele mesmo e nas suas categorias ou esquemas de entendimento, mas para o narrador, mediante as atualizações e formatações que este efetiva sobre si mesmo?

E se voltássemos agora à configuração clássica da entrevista, qual pode ser então a única pertinência do questionamento do pesquisador ao pesquisado, a não ser a de visar esclarecer o primeiro quanto aos motivos e às intrigas do segundo, permitindo-lhe entender claramente a variedade e a singularidade dos seus modos de existência? Essa é a única maneira, para a pergunta e para o perguntador, reentendidos no seu sentido comum, de continuar "seguindo os atores".

\section{ABORDAGEM METODOLÓGICA II: ANALISAR AS ENTREVISTAS BIOGRÁFICAS}

O que se faz com essa palavra do outro? Em um artigo, já de longa data, Jean-Claude Passeron, ao interrogar enquanto sociólogo o uso do material biográfico, enuncia a pergunta genérica à qual, segundo ele, esse material deve permitir responder: "O que faz a individuação de uma vida de indivíduo?" E prossegue: "Percebe-se que, assim que colocada, tal pergunta comporta uma multiplicidade de outras: uma vida, como se conta isso? Como se analisa isso? Será que se analisa isso como se conta? Em que sentido se pode falar da estrutura de uma individuação 
ou da estrutura de uma história individual? A pesquisa de tal estrutura é pensável teoricamente e realizável empiricamente?" (1989, p. 17). Mais de vinte anos passados, essas perguntas permanecem vivas e continuamos a nos interrogar sobre os operadores e os analisadores mais adequados para construir a compreensão do relato biográfico. Porém, antes de nos precipitarmos rumo a esta ou aquela grade de leitura ou modelo de interpretação, é preciso tentar compreender bem o que está em jogo da relação com o real, com o vivido, no relato que o narrador faz.

\section{O RELATO ENTRE TEXTO E AÇÃO}

O recurso ao relato coloca, de fato, um temível problema epistemológico e metodológico. A dificuldade consiste, em primeiro lugar, em circundar o que está em jogo no relato entre o "ato de viver", o "ato de contar" e o texto produzido pela atividade narrativa. Nisso consiste todo o empreendimento teórico de Paul Ricoeur em Temps et récit (1983-1985). Ele visa mostrar as relações que se estabelecem entre o fato de contar uma história e a dimensão temporal da experiência humana, apoiando assim uma na outra a construção de uma teoria do relato e a de uma teoria da ação. Sabemos que Paul Ricoeur analisa o relato como o produto de uma operação de configuração que ele designa sob o termo de "enredamento" ("mise en intrigue"). $\mathrm{O}$ enredamento apresenta uma tripla característica: transforma uma diversidade de acontecimentos ou incidentes sucessivos em uma história organizada, que se apresenta como um todo (configuração); junta e organiza elementos tão díspares como agentes, objetivos, meios, interações, circunstâncias, resultados (sintese do heterogêneo); e, por fim, transforma a relação de sucessão dos acontecimentos e dos encadeamentos finalizados, dando a cada elemento uma função e um sentido de acordo com a contribuição que este dá ao cumprimento da história contada (círculo hermenêtico) (idem, p. 102-103).

Enquanto operação constitutiva do relato, o enredamento tem, portanto, uma dimensão performativa. ${ }^{2}$ Ele age e produz ação, e a ação que produz se exerce sobre o texto enquanto forma, mas se exerce também sobre o agir humano a que se refere o texto. As duas dimensões de formatação textual e de configuração da ação são consubstanciais. O relato, então, não é somente o produto de um "ato de contar", ele tem também o poder de produzir efeitos sobre aquilo que relata. É nesse "poder de agir" do relato que se baseiam, aliás, as propostas de formação que se valem das "histórias de vida" para dar início a processos de mudança e de desenvolvimento nos sujeitos. E é igualmente o que fundamenta o interesse primordial da pesquisa biográfica pelo relato, já que este, pelas operações de configuração e de metabolização que introduz, é um poderoso "ator" - senão o ator principal - da biografização, uma vez que é na linguagem e pela linguagem do relato que os indivíduos constroem "o mundo interior do mundo exterior" (Alheit; Dausien, 2000, p. 276).

A partir daí, o problema epistemológico que o recurso ao relato de vida coloca é, por um lado, o da natureza da relação entre o texto e a ação - entre os

2 É chamado de performativo um enunciado que efetua, que "realiza" o ato que ele significa. Por exemplo: dizer "prometo", ou "juro", ou "batizo", é efetuar o ato da promessa, do juramento ou do batizado. 
recortes, as categorizações, os procedimentos de avaliação do texto e os recortes, as categorizações, os procedimentos de avaliação da ação. Ele levanta, por outro lado, a questão do que pode ser apreendido no relato daquilo que conecta o texto à ação, produzindo o sentido dessa relação: em outras palavras, e antes mesmo que se coloque a questão da interpretação (do "como interpretar"), ele levanta a questão do "objeto" a ser interpretado. Seguirei nesse ponto a análise desenvolvida por Jean-Michel Baudouin (2010) a partir da dupla afirmação: "O texto é a ação, o texto não é a ação”. O relato é ação, esclarece ele, na medida em que é uma atividade de linguagem, mas o relato não é a ação na medida em que o enredamento reconfigura a ação mediante operações de seleção e ordenamento, escolhas narrativas (velocidade do relato, forma de presença do narrador, postura enunciativa etc.), mediante modalizações e formas de valorização. Em razão disso, o relato não pode pretender restituir nem a totalidade, nem a fatualidade da ação. Toda a questão consiste então em pôr em relação "o texto como ação" com "a ação como texto", isto é, a experiência que o texto dá a conhecer. "O relato enquanto ação convida a escrutinar as operações de linguagem das quais ele é efetuação, a identificá-las e, assim, observar de perto como funciona o enredamento" (idem, p. 279). Mas, na medida em que não é redutível às ações que evoca, o relato convida a observar o trabalho hermenêutico realizado pelo sujeito na configuração, interpretação e avaliação de sua própria ação.

O enredamento, de fato, não tem apenas a dimensão de organização da ação no tempo, ele transforma as sequências de ação em sequências argumentativas que implicam uma posição enunciativa e avaliativa do autor - posição esta relativa, ao mesmo tempo, ao lugar que ele se atribui e às figuras que dá a ver de si mesmo, aos objetivos e às finalidades que persegue, às crenças e valores que são os seus, aos meios de que dispõe e aos obstáculos que encontra etc. O que o relato enreda é o mundo da intencionalidade, que é próprio do agir humano e nunca redutível a uma pura causalidade antecedente. É a esse mundo de intencionalidade e à atividade hermenêutica que o sujeito desenvolve sua própria ação que o relato dá acesso: "[...] o texto abordado como atividade permite analisar melhor a ação representada por este mesmo texto, isto é, discernir melhor o processo e o produto que dele resulta" (idem, p. 407).É esse "trabalho do sujeito", apreendido no que tem de irredutivelmente singular, que a pesquisa biográfica pretende atingir a fim de constituir uma compreensão e um conhecimento geral dos processos de biografização.

\section{ELEMENTOS DE LEITURA E ANÁLISE}

Os problemas metodológicos colocados por tal perspectiva constituem uma das questões candentes da pesquisa biográfica. A questão metodológica é inerente à pesquisa qualitativa em geral e aos estudos empíricos aos quais ela dá lugar (Olivier de Sardan, 2008; Paillé; Mucchielli, 2008), mas ela se situa no coração da pesquisa biográfica, na medida em que esta se dá como objeto da gênese individual do social nos processos de biografização. Presa entre a singularidade, de certa forma definicional de seu objeto, e a necessidade de uma formalização científica, a pesquisa biográfica deve elaborar instrumentos e métodos que lhe permitam não somente conciliar essas duas exigências, como também responder metodologicamente à questão que ela coloca teoricamente, a saber, a da fabricação "do mundo interior do 
mundo exterior", da metabolização e da apropriação pelo indivíduo dos ambientes de toda sorte que são os seus.

Não há de causar surpresa o fato de que os instrumentos de observação e os modelos de análise solicitados procedam, por um lado, das ciências dos textos e dos discursos (narratologia, linguística pragmática, análise do discurso) e, por outro lado, de diversas teorias que têm por objetivo descrever e categorizar a ação (teorias da ação). O quadro de uma comunicação é muito estreito para fazer um diagnóstico formal dessas abordagens, mas alguns exemplos de pesquisas realizadas com tais instrumentos podem dar uma ideia.

Começaremos pela obra, que se tornou quase um clássico, dos sociólogos Didier Demazière e Claude Dubar (1997), Analyser les entretiens biographiques. L'exemple de récits d'insertion. $\mathrm{O}$ estudo visa reconstituir o percurso de jovens que saíram do colégio sem o exame de conclusão de segundo grau (baccalauréat) e são entrevistados sete ou oito anos depois sobre sua experiência de inserção. Considerando que é ao relatar suas experiências que o sujeito produz as categorizações que lhe permitem apropriar-se do mundo social e definir nele seu lugar, os autores se dão por tarefa "estudar a categorização atuante na linguagem como constituição de um mundo simbólico estruturado que dá conta das práticas do locutor” (p. 81). O método de tratamento utilizado inspira-se na análise estrutural da narrativa (Barthes, Greimas) e visa identificar e compreender as estruturas de significações produzidas a partir dos elementos linguísticos e de suas relações. Recolhidos sob a forma de entrevistas não diretivas, os relatos são submetidos a uma análise destinada a identificar as ordens de categorização e de valorização das pessoas entrevistadas por meio das estruturas sequenciais (sintaxe das ações), actanciais (sintaxe dos "personagens") ou argumentativas (opiniões, julgamentos) utilizadas. Esse modo de proceder leva a pôr em evidência tipos de relato que representam os processos típicos de construção identitária e a reconstituir os "mundos socioprofissionais" correspondentes.

Darei a seguir dois exemplos colhidos na corrente das histórias de vida em formação. Trata-se, para o primeiro, da obra fundadora de Gaston Pineau e Marie-Michèle, Produire sa vie. Autoformation et autobiographie (1983), que está finalmente sendo reeditada. O projeto dos autores é de explorar os processos de autoformação com base no relato ou nos relatos de Marie-Michèle, jovem do Québec (Canadá), esposa, mãe e "do lar", engajada num processo de tomada de palavra, de narração de si, de reflexividade sobre seu percurso e de apropriação de um poder de agir autônomo, especialmente em face do seu lugar de mulher na sua sociedade e no seu meio. A "ana-síntese da autoformação de Marie-Michèle" desenvolvida por Gaston Pineau apoia-se num aparelho analítico que tem por fundamento as teorias da ação (mais precisamente a "ecologia da ação" de Abraham Moles) e lhe permite iluminar os fatores intervenientes nos processos de autoformação. Trata-se, por um lado, de uma fenomenologia dos atos que estabelece uma distinção entre ação, acontecimento, transação, interação, medindo cada um deles em razão da sua dinâmica autógena ou heterogênea e, por outro lado, de uma tipologia dos espaços e das relações que unem os sujeitos a cada um deles (relação com o corpo, com o outro próximo, com a moradia, com a vizinhança, com o espaço social, com o mundo e com o metamundo). Entre os indicadores retidos na identificação dos processos de autoformação, um 
lugar central é atribuído à transação definida como estabelecimento de uma relação entre dois elementos e ponto de articulação entre a economia interna do vivente e seus ambientes externos. A identificação e o tratamento cruzado desses indicadores permitem tornar legíveis os princípios estruturais que organizam o percurso de autoformação da narradora, ao mesmo tempo em que dão conta de sua singularidade.

Um exemplo mais recente é a análise, realizada por Jean-Michel Baudouin (2010), dos relatos de vida escritos por estudantes de pedagogia sobre seu percurso de formação. $\mathrm{O}$ encaminhamento adotado conjuga perspectivas teóricas plurais oriundas tanto das ciências do texto como das teorias da ação e da hermenêutica para "aproximar-se do que fazem os autores do corpus, isto é, das formas discursivas que assume a atividade hermenêutica situada na origem da produção narrativa" (idem, p. 9). Ao apoiar-se no estudo comparativo dos formatos e das velocidades de relato, o autor desenvolve, em particular, um modelo de "economia cinética" dos relatos, em outras palavras, da amplitude e da dinâmica dos movimentos da narração. Ele distingue, por exemplo, relatos que privilegiam movimentos lentos e recorrem prioritariamente ao "quadro" (cenas sincrônicas de tipo romanesco) e relatos que privilegiam movimentos rápidos e recorrem ao "resumo" ou "summary" (cenas diacrônicas). Esse tipo de análise permite ter acesso às formas singulares que toma o enredamento nos narradores e à maneira como eles se colocam em cena enquanto "atores" do seu percurso de formação.

Tomarei meu último exemplo na pesquisa que realizei, na linha da hermenêutica objetiva desenvolvida na Alemanha, ${ }^{3}$ com jovens mulheres moradoras de três grandes cidades da França e da Alemanha (Paris, Frankfurt e Berlim). Aqui eu me permitirei avançar um pouco mais do que o fiz até agora na descrição da pesquisa e no encaminhamento implementado.

As jovens mulheres, cujos relatos tenho recolhido, têm entre 20 e 30 anos de idade. Provêm de meios sociais diferentes, têm percursos escolares, universitários, semiprofissionais ou profissionais igualmente diferentes. Algumas vivem ainda na casa dos pais, outras vivem sozinhas ou em casal. A faixa etária escolhida corresponde a um período característico da passagem de estatuto $\left(\right.$ Statuspassagen) ${ }^{4}$ e, de fato, a maioria das minhas informantes está numa fase de transição acumulada, entre a adolescência avançada e a idade adulta, entre os estudos e a vida profissional, entre a família e a vida de solteira ou de casal. Esses períodos de transição e de passagem de estatuto constituem

3 Ao propor-se reconstruir as estruturas objetivas de significação dos textos, a hermenêutica objetiva desenvolve uma leitura interpretativa dos materiais biográficos que tende a superar a oposição entre vivido e linguagem, sujeito e objeto, individual e social. Ela instaura um encaminhamento que tenta reconstituir, por meio da análise das estruturas textuais, a maneira como os locutores constroem as constelações de ações, acontecimentos, experiências de sua vida para fazer delas figuras que, por sua vez, permitirão integrar elementos novos, tudo isso num processo nunca concluído de sintetização da experiência. Para uma apresentação detalhada, ver Delory-Momberger, 2000/2004, p. 224-240.

4 A pesquisa biográfica alemã (Biographieforschung) interessou-se particularmente pela noção de passagem de estatuto a ponto de fazer dela uma linha específica de pesquisa. Ver, em particular, os quatro volumes reunidos e editados sob a direção de Walter R. Heinz (2001), com o título de Statuspassagen und Lebenslauf(Passages de statut et cours de la vie). 
zonas de incerteza e de menor previsibilidade da existência. Por essa razão, são marcados por um trabalho biográfico intenso destinado a compensar uma falta de referências socioestruturais, a assegurar continuidade e coerência numa "história" cujas linhas e contornos permanecem imprecisos. Constituem, por isso, um campo de observação privilegiado dos processos de reflexividade biográfica postos em prática pelos atores.

O dispositivo adotado consiste em acompanhar essas jovens mulheres ao longo de um ano, durante o qual eu as encontro com intervalos regulares para proceder a entrevistas biográficas (e também retratos fotográficos). Na primeira sessão, peço que me contem o que se passa na sua vida presente, que digam o que, na opinião delas, desempenhou um papel nessa sua situação e como encaram o seu futuro. Nos encontros seguintes, elas colocam o que mudou ou não, o que se desenvolveu ou não em sua vida, assim como nas representações que elas têm de si próprias e de sua situação (na sua maneira de "ver as coisas").

Chego agora à análise das produções biográficas para as quais utilizei as seguintes categorias (acrescentarei, a cada vez, algumas observações de ordem geral ou exemplos relativos a uma das minhas informantes, "Catherine"):

a) A primeira categoria é a das formas do discurso: ela se refere à utilização por parte de minhas informantes de diversos modos de organização discursiva (narrativo, descritivo, explicativo, avaliativo) e às relações que se estabelecem entre eles. Cada uma dessas formas do discurso é suscetível, por sua vez, de ser categorizada. É o caso, em particular, do modo narrativo que se pode articular em diversos tipos de relato segundo os modelos biográficos de referência.

Uma observação de conjunto se impõe quanto à natureza e alcance das produções colhidas: o dispositivo implementado e as orientações dadas induzem a produção de relatos cuja função é mais descrever e explicar o presente, ou eventualmente antecipar o futuro, que reconstruir o passado, particularmente o passado longínquo. Eles têm mais relação com a autoapresentação do que com a narração autobiográfica propriamente dita. As produções se apresentam como fragmentos ou minirrelatos justapostos, mas que revelam, de uma sessão a outra, uma preocupação quanto à articulação, aliás mais temática que propriamente narrativa. Na verdade, minhas informantes usam o presente nos seus relatos, as histórias que contam sobre si mesmas são histórias em curso, histórias que se procuram. Então, elas não somente contam como também agem seu relato de maneira performativa, usam-no para agir biograficamente sobre si mesmas, investindo o relato como o lugar de um debate consigo mesmas, de um exame do que elas querem e do que elas podem, de um cálculo negociado entre suas aspirações, os seus projetos e os recursos internos ou externos de que dispõem.

b) A segunda categoria é a do esquema de ação $0^{5}$ que as narradoras utilizam, isto é, da atitude que adotam de forma recorrente na sua relação com as situações, com os acontecimentos, e na forma como agem e reagem. Entre esses esquemas de ação, podemos distinguir:

5 Valho-me aqui de uma categorização elaborada por Walter R. Heinz (2000, p. 165-186). 
- Um agir estratégico que se caracteriza por uma atitude de planificação e de negociação ligada a representações e a posições profissionais relativamente asseguradas;

- Um agir progressivo caracterizado por uma atitude de exploração das situações e de construção progressiva;

- Um agir arriscado em que o indivíduo busca conciliar opções de trabalho e interesses ou talentos pessoais;

- Um agir na expectativa em que o indivíduo se coloca na posição de "ver o que vai acontecer" e se entrega às circunstâncias.

Essa categorização é observável no nível da organização do relato, bem como do léxico relacionado com a ação (no emprego dos verbos, em particular). Os trechos deliberativos constituem igualmente um lugar de escrita e de observação desses esquemas de ação. Por exemplo: os relatos de "Catherine" obedecem a um esquema progressivo de ação. Eles se organizam em torno dos seus interesses culturais e profissionais (a educação, o teatro, o sapateado, o mundo dos surdos, a natureza): "tenho interesses diversificados", diz ela, deformando significativamente a expressão idiomática francesa. ${ }^{6}$ Cada um desses interesses é objeto de uma exploração prévia antes de ser progressivamente afastado em favor do último interesse retido: a educação das crianças surdas. Suas buscas para encontrar emprego nesta área obedecem também a um princípio de progressividade: faz tentativas sucessivas no decorrer das quais experimenta diversos aspectos de deficiências e de instituições ligadas à surdez antes de privilegiar um tipo de deficiência e de trabalho.

c) A terceira categoria é a dos motivos recorrentes ou topoi (do grego tópos, lugar-comum), que tematizam e organizam a ação do relato, agindo nele como lugares de reconhecimento e chaves de interpretação da vivência (embora o narrador não tenha forçosamente consciência disso). É particularmente na escrita desses topoi, desses lugares privilegiados, que os narradores constroem um sentimento de si próprios e das suas formas próprias.

$\mathrm{Na}$ tematização de seus relatos, Catherine recorre a um tópos duplo: por um lado, o tópos da "vocação" "Desde pequenina, tenho a impressão de ter algo a fazer nesta terra"), vocação que tem como centro a ajuda ao outro ("quero ajudar os outros, ser útil em algo"). E, por outro lado, o tópos da dificuldade de engajar-se num "ramo" em detrimento dos outros. Ela mesma se compara a uma "árvore" que não consegue renunciar a nenhum dos seus "ramos".

6 A expressão idiomática francesa assinalada pela autora "J'ai plusieurs cordes à mon arc" ("Meu arco tem várias cordas") é usada quando o sujeito quer significar que tem várias possibilidades (de solução) numa situação determinada. Porém, na situação aqui evocada, a informante declara: "J'ai plusieurs branches à mon arc" ("Meu arco tem vários ramos") (N. da T.). 
d) A quarta categoria se refere à gestão biográfica dos topoi em virtude da realidade socioindividual. Essa categoria concerne à confrontação e à negociação entre os topoi, as disposições e recursos efetivos (pessoais e coletivos), e as restrições socioestruturais. No discurso propriamente narrativo, essa confrontação pode traduzir-se por "choques" entre padrões biográficos veiculados pelos mundos sociais e as biografias de experiência. Ela é também observável nas fases deliberativas e avaliativas no decorrer das quais os autores apreciam, negociam, ajustam sua ação e a realidade socioindividual.

$\mathrm{Na}$ gestão biográfica dos topoi, Catherine encontra a realidade: por um lado, a realidade das crianças surdas portadores de outras necessidades especiais e, por outro, as condições materiais de trabalho. Ela deve constantemente dar provas de novas capacidades de adaptação: "É preciso se adaptar sem parar", diz ela para resumir suas experiências nas instituições de surdos. Ela vê também o problema da defasagem entre a teoria e a realidade da ação, "o que podemos aprender na escola, as reflexões que podemos ter e como abordar a excepcionalidade". E é finalmente a "lei da realidade" que a conduz a reter uma orientação: o segundo tópos desaparece na narração a partir de uma escolha voluntarista feita depois de meio ano, já que é mesmo necessário decidir-se em favor do "ramo" dos surdos.

Esta pesquisa me incita a desenvolver uma teoria do relato biográfico como lugar da gênese socioindividual. $\mathrm{Na}$ literariedade e na performatividade dos seus relatos, minhas informantes trabalham para ligar as experiências que fazem de si mesmas às realidades socioestruturais em que agem. Pelo trabalho biográfico que realizam sobre si mesmas, num período de incerteza e questionamento de sua identidade pessoal e social, experimentam assim sua biografia, isto é, a maneira como escrevem-agem sua história.

\section{CONCLUSÃO}

Concluirei por uma observação que é um convite à modéstia naquilo que empreendemos e, ao mesmo tempo, ao orgulho por aquilo que empreendemos. Todos os protocolos metodológicos - os que acabei de evocar, entre muitos outros - têm, ao mesmo tempo, seu alcance e seus limites. Qualquer que seja seu grau de tecnicidade e de sofisticação (por vezes, muito elevado), sua utilização não acontece sem uma dose de "bricolagem" (no sentido em que Lévi-Strauss usa esse termo). E essa bricolagem é, afinal, o signo e a garantia de uma busca "humana" de compreensão e de conhecimento empreendida por seres singulares e endereçada a outros seres singulares. Essa ambição, talvez louca, de atingir as próprias fontes e os modos de efetuação da singularidade individual só pode trilhar os caminhos de uma "hermenêutica da relação" em que o pesquisador empreende, ele também, um "trabalho do sujeito", tanto quanto o autor do relato, e em interação com ele. Talvez o pesquisador, mesmo quando "armado" de seus modelos e grades, não faça e não possa fazer nada a não ser "contar" por sua vez aquilo que lhe "contam" os relatos dos outros. É pouco e é muito, é o preço de uma ciência "humana”- e é seu tesouro. 


\section{REFERÊNCIAS}

Alheit, Peter; Dausien, Bettina. Die biographische Konstruktion der Wirklichkeit. Überlegungen zur Biographicität des Sozialen. In: Hoerning, Erika M. (Hrsg.). Biographische sozialisation. Stuttgart: Lucius \& Lucius, 2000. p. 257-284.

Baudouin, Jean-Michel. De l'épreuve autobiographique. Contribution des histoires de vie à la problématique des genres de texte et de l'herméneutique de l'action. Berne: Peter Lang, 2010.

Delory-Momberger, Christine. Les histoires de vie. De l'invention de soi au projet de formation. Paris, Anthropos, 2000/2004.

- Biographie et education. Figures de l'individu-projet. Paris, Anthropos, 2003. . Histoire de vie et recherche biographique en éducation. Paris: Anthropos, 2005.

- La condition biographique. Essais sur le récit de soi dans la modernité avancée.

Paris: Téraèdre, 2009.

Demazière, Didier; Dubar, Claude. Analyser les entretiens biographiques. L'exemple des récits d'insertion. Paris: Nathan, 1997.

Heinz, Walter R. Selbstsozialisation im Lebenslauf. Umrisse einer Theorie biographischen Handelns (Autosocialisation dans le cours de la vie. Esquisse d'une théorie de l'agir biographique). In: Hoenning, Erika M. (Hrgs.). Biographische sozialisation. Stuttgart: Lucius \& Lucius, 2000. p. 165-186.

. Statuspassagen und Lebenslauf(Passages de statut et cours de la vie). Weinheim/ München: Juventa Verlag, 2001.

Olivier de Sardan, Jean-Pierre. La rigueur du qualitatif. Les contraintes empiriques de l'interprétation socio-anthropologique. Louvain-la-Neuve: Academia-Bruylant, 2008. Paillé, Pierre; Mucchielli, Alex. L'Analyse qualitative en sciences humaines et sociales. Paris: Armand Colin, 2008.

Passeron, Jean-Claude. Biographies, flux, itinéraires, trajectoires. Revue française de sociologie, v. XXXI, n. 1, p. 3-22, 1989.

Pineau, Gaston; Michèle, Marie. Produire sa vie. Autoformation et autobiographie. Montréal: Editions Saint-Martin. Réédition aux Editions Téraèdre, 2012. [1. edição 1983].

Ricoeur, Paul. Temps et récit. Paris: Seuil, 3 tomos, 1983-1985.

\section{SOBRE A AUTORA}

Christine Delory-Momberger é doutora em ciências da educação pela Universidade de Paris 8. Professora da Universidade de Paris 13. E-mail: christine.delory@asihvif.com 


\section{RESUMOS/ABSTRACTS/RESUMENS}

\section{CHRISTINE DELORY-MOMBERGER}

\section{Abordagens metodológicas na pesquisa biográfica}

O artigo aborda a pesquisa biográfica, seus pressupostos epistemológicos, suas práticas metodológicas e alternativas de análise. O texto inicia com uma discussão sobre o que constitui especificamente o projeto epistemológico da pesquisa biográfica, confrontando sua perspectiva teórica com a abordagem sociológica. Nesse sentido, assume a concepção de indivíduo como ser singular, biográfico, que possui sua própria experiência. A seguir, desenvolve os aspectos metodológicos da pesquisa biográfica, considerando o material biográfico propriamente dito, as formas típicas de coleta com a entrevista biográfica, sua condução e suas implicações no trabalho de campo. Finaliza com uma discussão sobre a análise das entrevistas biográficas, por meio das seguintes categorias: "formas do discurso", "esquema de ação", "motivos recorrentes" e "gestão biográfica", presentes no material coletado.

Palavras-chave: pesquisa biográfica; projeto epistemológico; entrevista biográfica.

\section{Methodological approaches to biographical research}

This article discusses biographical research, its epistemological assumptions, methodological practices and alternatives of analysis. The text begins with a discussion of what specifically constitutes the epistemological project of biographical research, comparing its theoretical perspective to the sociological approach. In this sense, it takes the concept of the individual as a singular, biographical being who has his or her own experience. Next, it develops the methodological aspects of biographical research, considering the biographical material itself, the typical forms of collection with biographical interviews, their conduction and their implications for fieldwork. It ends with a discussion on the analysis of biographical interviews through the following categories: "forms of discourse", "framerwork for action", "recurring motifs" and "biographical management", present in the material collected.

Keywords: biographical research; epistemological project; biographical interview.

\section{Abordajes metodológicos en la investigación biográfica}

El artículo aborda la investigación biográfica, sus presupuestos epistemológicos, sus prácticas metodológicas y alternativas de análisis. El texto empieza con una discusión sobre qué constituye especificamente el proyecto epistemológico de la investigación biográfica, confrontando su perspectiva teórica con el abordaje sociológico. En ese sentido, asume la concepción de individuo como ser singular, biográfico, que posee su propia experiencia. Luego, 
desarrolla los aspectos metodológicos de la investigación biográfica, considerando el material biográfico propiamente dicho, las formas típicas de recopilación de datos con la entrevista biográfica, su conducción y sus implicaciones en el trabajo de campo. Termina con una discusión sobre el análisis de las entrevistas biográficas por medio de las siguientes categorías: "formas del discurso"; "esquema de acción"; "motivos recurrentes" y "gestión biográfica", presentes en el material recopilado.

Palabras clave: investigación biográfica; proyecto epistemológico; entrevista biográfica. 